\title{
Mysticism as a Form of Knowledge and a Method of Communication
}

\author{
Dmitriy Utkin ${ }^{1,2 *}$ \\ ${ }^{1}$ Faculty of Humanities and Social Sciences, Peoples' Friendship University of Russia, Moscow, Russia \\ ${ }^{2}$ Gapar Aytiev's street 28, Bishkek, Kyrgyz Republic \\ *Corresponding author. Email: wiedzmin39@bk.ru
}

\begin{abstract}
This article devoted to the analysis of mysticism as a cultural phenomenon. The author considers mysticism as a form of non-traditional cultural knowledge in relation to everyday and scientific knowledge. The article also examines the role of mysticism and mystical experience in religious culture. As part of the socio-philosophical analysis of mysticism, the study of the communicative aspects of this cultural phenomenon was carried out: the features of the language of the mystical experience, as well as the communicative interaction of the subject of mystical knowledge with society. As a result, it was revealed that the subject of mystical knowledge ignores the language constructions of everyday speech due to the fact that the usual form of speech does not allow expressing deep, expressive mystical experiences. In this regard, mystics construct their narrative and texts using metaphors and apophaticism, it can be understood by other members of the religious-mystical tradition, but remain misunderstood by ordinary people.
\end{abstract}

Keywords: mysticism, mystical experience, culture, communication, language, metaphor, knowledge,

text

\section{INTRODUCTION}

Mysticism is an ancient cultural phenomenon that has accompanied the public consciousness for thousands of years. Although mysticism is quite an ancient phenomenon, it is not static in sociocultural development. Like any other social phenomenon, it is historically variable. Mysticism, more than religion, can be described as a plastic and dynamic form of spiritual activity. Religion is dogmatic, but mysticism rejects dogmatism. From time to time, the traditions and practices preached in mysticism change. Mysticism often appears as an original expression of its era. For example, mysticism of the Renaissance allowed cultural figures to challenge the dogmatic views of scholastic philosophy. It resulted in naturalistic mysticism and a return to Neoplatonism. In modern mysticism, there is a combination of mystical trends and movements - new Age, which posed a number of problems for culture and philosophy. Here we are talking about new views on the nature and essence of man, about a different perception of the human psyche and its development, and about attempts to manifest other non-rational forms of knowledge. In modern culture, mysticism exists in the form of classical teachings in the bosom of religious traditions such as Tantrism, Zen, Kabbalah, Hasidism, Hesychasm, Sufism, as well as in the form of new teachings that appear in the $\mathrm{XX}$ century (wicca, neo-shamanism, neo-druidism, etc.). So, the main goal of this article is to consider mysticism as a special form of knowledge, as well as its relationship with other parts of the general stock of social knowledge, such as religious knowledge, scientific and everyday. Due to the fact that mysticism is an unusual form of cognition and knowledge, it assumes the presence of some communicative aspects in the translation of mystical experience.

The essence of mysticism is not only in its perception as a specific type of activity in the spiritual culture of society. Mysticism is knowledge that is based on a supersensible and intuitive method of knowing another reality. Since mysticism offers a person special knowledge based on mystical experience, the transmission of this type of knowledge to others assumes its own specifics. Aspects of communication in mysticism are complex and ambiguous. However, in every culture, mysticism as a way of communication is expressed in certain linguistic patterns such as inexpressibility, paradoxical, metaphor. 


\section{MYSTICISM AS AN UNCONVENTIONAL FORM OF CULTURAL KNOWLEDGE}

An integral and rather interesting feature of mysticism is its influence on human cognition. Being an extremely unconventional form of knowledge, mysticism always offers different views on the interpretation of realness and its perception. Mysticism is a specific form of knowledge about what lies beyond the everyday and social stock of knowledge. Mysticism refers to the knowledge of a different being or other types of reality when it comes to non-traditional mystical currents (occultism ${ }^{1}$ ). For the mystic, the observed reality is only a part of the transcendent reality that he encountered in the practice of altered states of consciousness, or even an illusion. Therefore, an elementary knowledge of reality and the surrounding nature is not particularly valuable for him. Everyday knowledge, based on life experience, experiences and impressions of a non-spiritual nature, cannot attract the interest of the mystic, especially if he is guided by the axiomatic knowledge that reality is something to be overcome and rejected (Gnosticism2).

It is from this same premise that the mystic's attitude to scientific knowledge about the structure of existence proceeds. Scientific ideas are deeply materialistic. They deny the existence of another reality, from which the visible part of the space habitual for human perception unfolds. Scientific knowledge requires a strict rational and logical system of proof of certain statements about processes in the world. At the one hand mysticism gives the knowing subject, who is directly addressed to it, a truth that does not require proof. This knowledge is achieved through direct experience. In addition, the scientific consciousness is harshly critical of the object of knowledge and spiritual research of the mystic. Science denies God or the absolute principle as an ontological first cause. This is the difference between the mystic and science as part of the system of social knowledge.

\section{THE ROLE OF MYSTICISM IN THE RELIGIOUS CULTURE}

The knowledge of the mystic is always based on such experiences as we call mystical. The very combination of "mystical knowledge" already makes it clear that we are not talking about ordinary religious knowledge. Mystical knowledge is the

For example, occultism, as a kind of mystical teachings, assumes the existence of several types of reality as the astral plane and the mental plane of being.

In Gnostic mysticism, the physical world was considered an imperfect creation of the Demiurge and was considered a prison for souls. The Gnostics preached that the true God and real reality can be achieved when the adept completely rejects the habitual existence. totality of the experience of the mystic, the experience that he acquires in his practices of comprehending another reality, "nothing" or the spiritual absolute. His experience, which is the experience and feelings that arise from communication with the transcendent, is characterized by direct interaction with the object of mystical knowledge, excluding the mediation of the clergy, religious texts or the religious experience of other people. Knowledge based on mystical experience is always the result of personal experiences. In religious culture, the figure of a mystic, his experiences and experiences are perceived ambiguously. Mysticism is known to fall out of favor with the Orthodox view of the Church. Mechkovskaya N. B. writes: "in "organized" religions - with a developed Church, canonized and therefore closed doctrine, with long - established traditions of religious life-mystical impulses are not encouraged. Mysticism is a zone of free thought, religious search and possible discoveries, and "a direction of thought with an anti-legal and antischolastic bias" [1]. Mystical experience differs from religious experience in that it is the result of an individual's deep search for divine truth, coupled with spiritual transformation. A mystical experience can be burdened with negative emotions Religious experience most often based on superficial and joyful experiences. The mystical experience of a mystically gifted person is much deeper and more intimate. In such an experience, the mystic experiences the realization of the divine in the immediate and living stage where the personal presence of God is revealed. The fact of a personal, vivid and emotional experience of God reveals to the mystic a different side of religious feelings and allows him to doubt the general, superficial religious dogmas of Church teaching. Therefore, the mystic interprets his experience of God and other existence differently from what is prescribed in the general canonized religious scripture. This freedom in metaphysical views caused a negative and wary attitude towards mystics and the practice of mysticism within the religious institution. The mystic sees traditional religious knowledge as superficial, not corresponding to what he experiences in his religious experience.

The attitude of the mystic to religious knowledge often follows the path of apophatic theology. The mystic discards all definitions that are incommensurable to God (or higher reality) and that do not correspond to him. In the end, he comes to the definition of God as "nothing". This trait characterizes most of the mystical teachings in the world's religious cultures. Such views are quite clearly indicated in the mystical texts of the ancient Indians in the Upanishads. Here, Brahman, which is the highest reality, is perceived and denoted by mystics through negation as "not this, not this" (na 
iti, na iti) $[2]^{\mathrm{P} .55}$. In Taoism, the category "Tao" is also defined as something that has no name and cannot be named in principle. The Tao of Chinese mystics is a kind of inexplicable and incomprehensible category that resides in everything as a universal law of being, as well as a unique way of each thing. The Tao is often defined by such a vague expression as "the way, but not this way" or the Tao, which may be called, is not the transcendent Tao. The name that can be called is not a permanent name. It is the nameless, the beginning of everything on the Earth [3]. In Kabbalah, the religious and mystical teaching of Judaism, there is a designation of God as "Ein-Sof". The term "Ein-Sof" is used to reflect the infinity, infinity of God, as well as his unknowability due to the fact that God is out of touch with the world as an incomprehensible "nothing".

\section{MYSTICAL EXPERIENCE AND ITS SPECIFIC EXPRESSION ON THE VERBAL LEVEL}

Despite apophatic views, mysticism is a way of communication. Throughout the existence of human society, people who have touched the mystical try to express their unusual experiences and experiences. Mystical experiences are unique, far from commonplace, and difficult to communicate. Often, the fate of a mystic is a traditional silence or an indistinct narrative presented as metaphors, semantic paradoxes, and innuendos. W. James, as a representative of pragmatic philosophy and a researcher of the typology of religious experience, was one of the first to identify this communicative aspect of mysticism. In his classic work "The Varieties of Religious Experience" William James writes: "ineffability is the handiest of the marks by which I classify a state of mind as mystical is negative. The subject of it immediately says that it defies expression, that no adequate report of its contents can be given in words. It follows from this that its quality must be directly experienced; it cannot be imparted or transferred to others $[4]^{\mathrm{c} .303}$." Thus, the main problem that arises in the study of mysticism and its communicative aspects is that the mystical experience transcends the usual for us everyday language. A mystic's description of his mystical experiences is always a text or story that inherently has in its structure the details of the description of the experienced states.

The mystic uses language in expressing his experience that may be unintelligible to most people. The mystic builds up his experience as knowledge of the truth revealed to him in another reality. This truth he presents as ineffability, inexplicable, indefinite, and is inclined to keep silent about it. The experience of a mystic is always based on peak experiences and feelings, and it is difficult to fit his insights into a verbal framework. Therefore, at the verbal level of everyday speech, the mystic does not find suitable language constructions for a specific description of his special experiences or the truth revealed to him. It is for this reason that many authors, including mystics themselves, believe that mystical experience is Ineffability. "Direct analysis of mystical experiences is impossible, scientists deal with their expressions and interpretations, which means that doubts about the possibility of studying "from the outside" experiences that cannot be verbalized are quite natural within the essentialist paradigm: its proponents consider the fundamental inexpressibility to be an essential property of mystical experience, due to its non-discursive nature, and insist on a radical break between the mystical experience itself and language, which is not a literal description of the phenomenological content of mystical experiences", writes T. Malevich [5] ${ }^{\text {P.117 }}$.

Still, you can disagree with this. Human cognitive processes cannot take place outside of the language process. And here mysticism, as a kind of cognitive activity, cannot exist in the form of a closed, purely non-linguistic sphere. Mystics themselves admit that their mystical experience is different from religious, everyday, or any other experience. This indicates the fact that mystics conceptualize it with a certain degree of success. The relationship of mystical experiences to language expressions, utterances, or texts cannot be reduced to the concept of distortion or interpretation in the process of narrating a mystical experience. "The focus on mystical experience, half-psychological, half-religious approach, which painted most of the studies of mysticism and excessive bloated problem of the relation of experience and interpretation - all of this is in research to the forefront, leaving behind the question of how is mysticism in the culture - no matter what is worth it "for" him... a mystical text can not only be seen as an interpretation, description, report, and especially the distortion of a primary, initially, this pure experience" $[4]^{\mathrm{P} .93}$. The experience of the beyond in the speech constructions of the mystic is inevitably expressed in a metaphorical description. The mystic in order to tell the layman about his mystical experiences selects words and expressions in a figurative sense, which are based on an approximate comparison or similarity of what he is trying to explain. Metaphorically speaking about "nothing" or about the "absolute", the mystic uses analogies taken from everyday speech. Without metaphors and parables, the mystic will not be able to evoke in the person listening to his mystical knowledge even a vague idea of what the mystic wants to tell. It should also be noted that the narrative of the mystic does not 
always indicate the inexpressibility of the experience of knowledge of the beyond. Naturally, we know many examples where mystics were extremely reluctant to talk about their experiences (Saint Teresa or Blessed Angela), but other mystics, on the contrary, always preferred to express their experience. Such mystics often had good abilities in the field of language and expression of their feelings, both everyday and mystical [4].

\section{MYSTICISM AS A DIALOGUE}

Mysticism is also a special type of
communication method. This type of communication does not always involve the practice of individual-to-individual communication. Mysticism is an ancient phenomenon in social practice. In the early stages of society, mysticism existed in a general religious complex of beliefs. The communicative feature of mysticism consists in contact with the transcendent, invisible part of our reality. Since ancient times, in shamanism, animistic or totemic cults, people have communicated with the spirits of primitive religions and mythologies. Mysticism is still a dialogue in one form or another. The mystic communicates with a higher reality or God in specific ways. Even when it comes to primitive mysticism, it is with the spirits and demons of primitive mythologies. Still, the mystic's communication with other people is possible. Interest in communication for a mystic comes when he meets another mystically minded individual. The mystic will always understand the mystic, so they both understand what they are talking about in their dialogue. Especially if they belong to a common religious and mystical tradition or adhere to common worldview ideas. The history of mystical teachings is full of examples when mystics live in a closed religious community, avoiding contact with the outside world. Within the framework of a common communication environment based on the perception of the mystical, they understand each other perfectly.

\section{MYSTIC AND COMMUNICATION}

It is important to consider another feature of communication in mysticism. It is known that the mystic spends his life in seclusion and tries to communicate with other people as little as possible. What is the problem with the mystic's disregard for communication with others who are not involved in the sphere of mysticism? For the mystic, first of all, it is important to communicate with the sacred reality, to know the secrets of another existence, the revealed truth and God. In order to maintain constant or systematic communication with the object of their mystical knowledge, the mystic must resort to a number of practices and exercises. These practices often involve physical solitude, since the mystic needs concentration for mental contemplation. This lifestyle is one of the reasons that reduces communication with other people to a minimum. It can also be noted that the mystic, by virtue of his way of life, becomes the owner of special types of worldview and worldview, thanks to which he sees the mystical side of being in every thing. Such a mystical view of the world inevitably causes misunderstandings among other people who are very far from the mystical. Over time, the fact that people don't understand him becomes irrelevant to the mystic. This does not cause him negative feelings, since the mystic feels himself attached to the divine truth, and accordingly he is aware of his peculiarity before others [7]. The mystic prefers a solitary lifestyle and rarely maintains communication until it is essential for the mystic to do so.

\section{CONCLUSION}

Despite many attempts to explore mysticism, it remains a poorly studied phenomenon of public consciousness. Mystical knowledge is a special type of knowledge that differs from religious, ordinary, and scientific knowledge, since this knowledge is based on experiences of a different type of being. Such mystical experiences are quite difficult to express vague, and seem meaningless or contradictory in verbal expression. This is due to the fact that everyday speech is not sufficient to express the entire spectrum of mystical experience that the mystic wants to tell about. However, it cannot be said that the mystical experience is inexpressible in principle. All the speech techniques that mystics use are the only way to somehow tell about their mystical insights or feelings. Without this type of communication, it would be impossible to carry out continuity in mystical teachings.

Mysticism as a cultural phenomenon is not limited to the above questions. This is a multifaceted and unique phenomenon requires a new methodology in its research. This is especially true in the realities of modern socio-cultural development, since in modern culture mysticism loses its marginal character. Today, mysticism is no longer perceived as a subject of interest for religious, esoteric orders and associations of a narrow circle of specialists. Mysticism as a social phenomenon acquires the features of a syncretic phenomenon. Against the background of the interaction of modern cultures, the mystical teachings of various religious traditions are mixed. In this regard, the phenomenon of mysticism acquires a new meaning in the study of it as a method of communication. We have considered the problems of classical examples of the problem of language and communication features in mysticism, but these problems are not fully investigated due to 
the distrust of mysticism in the scientific community. That is why it is necessary to put mysticism at the center of religious-philosophical and religious studies and make this most interesting socio-cultural phenomenon the subject of scientific analysis to identify the general features of its diverse manifestations in communication and culture. We can rightly assume that the study of mysticism is a social order of our time [8].

\section{References}

[1] N. B. Mechkovskaya. Language and religion: A Guide for students of humanitarian universities. - Moscow: Agency «FAIR», 1998. - $352 \mathrm{p}$.

[2] The Upanishads // Brihadaranyaka Upanishad. Ed. by O. F. Volkov, N. B. Kondyreva. - Moscow: NAUKA, 1992, $237 \mathrm{p}$.

[3] Lao Zi. Tao te ching. [Electronic resource:] https://www.sredotochie.ru/wpcontent/uploads/2013/02/lao-tszi_dao_de_tszin1.pdf1.pdf.

[4] W. James. The Varieties of Religious Experience A Study in Human Nature. - Moscow: Academic project, 2017. $415 \mathrm{p}$.

[5] T. V. Malevich. Theories of mystical experience: historiography and prospects. - Moscow: IFRAN, 2014. $175 \mathrm{p}$.

[6] Y. A. Stepanchuk. The problem of a mystical text. Interpretation and ineffability // Vestnik RUDN, ser. philosophy. No. 1 (9.) - Moscow, 2003. P. $92-102$.

[7] M. L. Ivleva, E. M. Kurmeleva, S. V. Rudanovskaya. Man and Society in the Context of Modernity/ Issues of Philosophy, №4. - Moscow: «Nauka» Publishing House, 2018. - P. 191-195.

[8] E. G. Balagushkin. Scientific and analytical consideration of mysticism // Philosophical thought. [Electronic resource:] https://nbpublish.com/library_read_ article.php?id=589. 